\title{
Linking Practice on Ancient Chinese Teaching and Classical Chinese Teaching in Middle School based on Rotation Classroom
}

\author{
Zhantao He \\ College of Literature, Bohai University, Jinzhou, 121013, China
}

hezhantao@126.com Keywords: rotation classroom; ancient Chinese teaching; classical Chinese teaching in middle
school; linking practice

\begin{abstract}
The ancient Chinese teaching and classical Chinese teaching in middle school has a close relationship, to realize the effective connection of both is the important problem in the process of teaching. Turn the classroom teaching mode provides a new thought and method to study and solve the problem. First of all, respectively study ancient Chinese teaching and classical Chinese teaching in middle school; Then the ancient writings in classical style teaching of middle school Chinese teaching and the related content; Finally, the research of turn the class under the ancient writings in classical style teaching of middle school Chinese teaching and cohesion. In this paper, the research has solved the key problem in the process of cohesion, but in practice, also need educators with era pace, renewal education idea, insisted on the principle of quality education, continuously explore the scientific teaching methods.
\end{abstract}

\section{Introduction}

The traditional teaching is the teacher lectures, students grasp the classroom speak content after class. However, with the rapid development of information technology and the great changes in living environment, cognitive thinking of people also slowly change, for learning method has a higher request, the disadvantages of traditional teaching are increasingly highlights: traditional teaching is that teachers one-way transmission of knowledge, students' learning autonomy has not been displayed; Traditional classroom teaching for all students, the teaching of middle school students individual differences are ignored; Due to the lack of good environment, lack of initiative of students outside the classroom, on the "absorption internalization" this link, the student to the migration of knowledge and understanding is not enough in-depth [1]. "Turn the classroom" is the independent learning theory, constructivism theory and blended learning theory as the foundation, to adjust the inside and outside the classroom, teachers are no longer take up classroom time to teaching information, will study the decision as to shift from teachers to students. Students to plan their own learning, learning, rhythm, style, and presents the way of knowledge, the teachers teaching method and the collaboration method is used to meet the needs of students and facilitate the personalized learning, goal is to make students obtain more real learning through practice. "Turn the classroom" make learning two processes reversal, in the" absorption internalization "this link, can the student extracurricular transferred to the classroom, in terms of learning and knowledge building, based on their practical ability and give priority to, the principle of their aptitude; "Turn the classroom" focuses on the autonomy of the classroom to the students, and teachers just through assistance and communication support student learning, students according to their own needs, the freedom to build their own knowledge system.

The ancient Chinese teaching and classical Chinese teaching in middle school and has a close relationship. Learn the ancient Chinese well, master the basic knowledge of ancient Chinese, improve the ability of reading ancient books, using relevant knowledge of the writings in classical style teaching, improve the level of middle school writings in classical style teaching, is the issue of Chinese language and literature majors must face. To realize the effective connection of both is an effective way to solve this problem, also is Chinese language and literature professional teachers 
must study problems. Turn the classroom teaching mode to study and provides a new thought and method to solve the problem.

\section{Ancient Chinese Teaching}

Ancient Chinese is a basic course of the undergraduate major in Chinese language and literature and tool. The teaching purpose is, in under the guidance of Marxism theory of linguistics, cultivate students' ability of reading ancient books. By basic theory and basic knowledge of ancient Chinese teaching, give priority to read ancient literatures, to make the students master the language of the ancient Chinese law, so that with the help of reference books to direct reading of ancient literature, critically inherit the ancient excellent cultural heritage in our country. The main content of teaching includes analects, common words and general theory of the three parts [2-5].

(1) Analects. The voluminous ancient Chinese classics and the ancient Chinese teaching material compilation of anthologies all is a long historical process of accumulation, has strong ideological content and artistic quality, with a strong vitality. Selected works of ancient laws and features of ancient Chinese is a focal point of the ancient Chinese teaching. Language as a tool, however, study of ancient Chinese, and master the characteristics and laws of ancient Chinese, in the end is to use it to read and understand the ancient anthologies. Analects teaching must pay attention to the language teaching of other aspects, including thought contains the aspects of theme, language skills and culture, and these aspects is easy to ignore the content of the selected works of ancient Chinese teaching, we should strengthen the teaching of these a few respects.

(2) Common words. Interpretation of ancient Chinese words and Summarization of the usage in ancient Chinese vocabulary means indispensable link in reading books and collusion. Ancient Chinese vocabulary has become the important content of classroom teaching. In the long-term teaching practice, summed up the common words and its teaching has a prominent features: common words with uncommon words have limits on fuzziness; Use content drab, isolated, is not conducive to centralized teaching; Uncommon, unfavorable teaching and understanding. According to the characteristics of the ancient Chinese common words, arranged in the teaching material content and lectures must adopt a more scientific method: strengthen the accuracy of word choice and science; According to the article word choice; Focus on selecting a larger number of common words, classification into teaching materials, self-study and consult for the student.

(3) The general theory. Ancient Chinese text, voice, vocabulary, syntax and culture, and many other content, is an important part of ancient Chinese teaching. General part of the study is about the basic theory of ancient Chinese study, master the general part involves knowledge, can accurately grasp the kernel of the ancient Chinese, in learning and reading the ancient literature can extrapolate, reach the level of mastery. Mainly includes the following contents: the dictionary annotation and ancient books of knowledge, knowledge of the vocabulary, grammar knowledge, and phonological aspects. Also includes about rhetoric, ancient books sentences and read ancient structure, odes and Parallel Prose text structure, etc.

Ancient Chinese teaching needs to adhere to the principle of theory with practice, and strive to make joint connection among analects, common words and general theory of the three parts. In guiding students to read the article, on the basis of general teaching, the students to the perceptual knowledge and rational understanding of ancient Chinese. At the same time, the study selection, should give priority to in order to explain words, especially article involved in the common word, we should grasp the nuances of the ancient Chinese word meaning and the nuances between synonyms and near synonyms, cultivate the students' ancient Chinese language, pay attention to embody the characteristics of language classes.

\section{Classical Chinese Teaching in Middle School}

Classical Chinese in classical style is an important carrier of ancient Chinese culture, has great cultural value and education value. High school writings in classical style teaching is an important part of Chinese teaching and learning, is the window of the middle school students' understanding 
of traditional Chinese culture and the starting point, to study the writings in classical style to help middle school students' use of language more flexible, improve the students' Chinese accomplishment and humanistic connotation.

(1) Do a good job of words and sentences teaching and make good base of Classical Chinese teaching. The modern Chinese vocabulary, syntax and rhetorical devices and the ancient literature language has the blood relationship. Classical Chinese text words teaching is the basis of the writings in classical style teaching, can explain the traditional model of word for word, abandon the past, guide students to use the text annotation and reference books, actively grasp the word meaning, carries on the preliminary translation. Let the student at the same time in the study of the writings in classical style, taste the knowledge of classical Chinese and commune with the ancients of achievement, further improve students' interest in learning Classical Chinese.

(2) Adopting the combination of three teaching methods. Classical Chinese teaching in middle school is both of an anthology analysis, also have related knowledge about; There are lectures, and extra-curricular reading guide. Not only wordings also aesthetic consciousness training. The operation of the achievements of these means is series methods: analects as platform, elegant sentence remembers and combined with the knowledge grasp; Understanding as the forerunner, the combination of reading and appreciation; Powered by classroom teaching, teaching method combined with stimulating students' interest.

(3) The classic Chinese teaching also teaches students to extrapolate [7]. Let students master the common content words and function words explanation is a focus of the writings in classical style teaching. Content words explain should give attention to two or more things arrives when interchangeability phenomenon and the change of parts of speech; Function words comprehension should not only know the meaning, but also find out usage. Understand the differences between ancient and modern meaning, the ancient and modern meaning to contrast and comparison. Study competition, let the students find out the similar phenomenon sentence in the passage, fully mobilize students' thinking, to explore in practice, in an atmosphere full of thinking about learning to improve students' ability.

\section{Related Content on Ancient Chinese Teaching and Classical Chinese Teaching in Middle School}

Associated content is characterized by the following four aspects [8]:

(1) Grammar knowledge and classic Chinese teaching. The use of the content words, content words can separate ACTS as parts of the sentence, namely lexical meaning and grammatical meaning of the word. Including verb, adjective and noun, etc.; The use of the function words and function words to denote doesn't make full sense of words, but there is meaning of words, grammatical meaning or function should grasp the part of speech, usage, and meaning. Including pronouns, adverbs, prepositions, conjunctions, and modal particles, etc.; Sentence pattern recognition, sentence pattern is the type of sentence structure. Including judgment sentences, passive sentences, double objects and object front, etc.

(2) Knowledge and writings in classical style teaching text. The determination of the structure analysis and the meaning of the Chinese characters, including the pictographic, one of the Chinese characters, Chinese characters of second self-explanatory, knowing the third Chinese characters, Chinese characters of the four echoism, conversion of the five Chinese characters, Chinese characters of six under the guise of; Ancient and modern words, word time has successively, with size range and a certain sense of a word or group of words. Different terms, the same pronunciation and meaning and form of a word or group of words; interchangeability characters, the ancient Chinese written language word homophones or nearly in general or under the guise of;

(3) The vocabulary knowledge and writings in classical style teaching. The difference between the ancient and modern meaning, including the meaning of many different, the emphasis of the meaning is different, the weight of the significance of different degrees, meaning the emotional color is different, meaning referred to anything different; In the evolution of the meaning of law, including the expansion of the meaning of narrowing of the meaning, the transfer of meaning; The 
determination of the meaning, including according to the font meaning, meaning is determined, according to the context according to determine meaning of synonyms or antonyms (Ed), according to the idiom meaning; Important vocabulary phenomenon, including a laparoscope, usually connected to a partial semantic copying words, continuous, monosyllabic word continuous use; Synonym discrimination, including the scope of the meaning of different sizes, different modal meaning characters, degree of meaning of different shades, different aspects of meaning focus, meaning different emotional color, meaning of grammatical functions are different, meaning the applicable objects; Types of word meanings, including the original meaning, under the guise of a word, and determine the type of word meanings.

(4) Other intellectual and classical Chinese teaching. Phonological knowledge, including understand the principle of dialect of interchange ability, and don't know the word in dialect; The ancient knowledge, can help to better understand meanings; Rhetoric knowledge, the correct analysis and the use of figures of speech, according to the specific language environment to determine whether a rhetoric method using appropriate and analyze the expression of rhetoric using effect; Cultural literacy, including astronomy, geography, calendar, temperament, high class, name, imperial examinations, custom, horses and chariots, and he finished all his house, and diet, etc.

\section{Linking Solution on Ancient Chinese Teaching and Classical Chinese Teaching in Middle School based on Rotation Classroom}

On the basis of my previous teaching and scientific research, combining with the results of predecessor [9-12], linking scheme proposed in this paper are as follows:

(1) System teaching ancient Chinese knowledge and supplement the relevant knowledge. As teachers of ancient Chinese language course should not only to the university of ancient Chinese teaching content, teaching target and teaching requirement, accomplish know fairly well, also want to the high school writings in classical style teaching content, teaching target and teaching requirement. Teaching of ancient Chinese knowledge, both must pay attention to its systemic also should pay attention to supplement relevant knowledge, make students better understand the outside. Appropriate supplementary basic knowledge of the history of Chinese language, let the students establish a view of language development, deepen the students understanding, helps to raise the level of middle school writings in classical style teaching of normal students.

(2) The teaching content should be pay attention to ancient and modern combination. Language is inheritance, is the source of ancient Chinese and modern Chinese is a flow, is the inheritance and development of ancient Chinese and modern Chinese in many directions and show the relationship between both. In relevant subjects of ancient Chinese, modern Chinese is the most closely relationship with it. On the arrangement of teaching contents and teaching focus, attention should be paid to deal with the problem with the modern Chinese; Ancient Chinese teaching should strengthen the contact with the modern Chinese, trains the student to apply the knowledge for ancient Chinese analysis emphatically the ability to solve the problem of language in reality, in order to achieve the purpose of the past.

(3) Making rich content of network teaching video resources. Teaching video can be recorded by curriculum on teachers, can also be used on the Internet looking for high quality open education resources. Teacher recorded video resources should be according to the actual situation of students, the teaching content targeted, according to the differences between students, should not only consider all, and to the individual. Video production to do reasonable interface, the style is unified, convenient management, pay attention to practical, clear navigation, accompanied by clear text introduction and help document, emphasize teaching topic point and design of the structure of the interactive strategy, learning platform to help students build rich content, attracting students actively participate in the video.

(4) Combine the ancient Chinese teaching and classic Chinese teaching of middle school. Chinese language teaching of middle school teachers should guide students to the ancient Chinese writings in classical style and knowledge relating to sort out contents, and consciously involved in the teaching content, help students are familiar with and understand the editor and the purpose of 
these writings in classical style knowledge, which involves the language knowledge and rules, what constitutes the teaching system, causes the student to clear learning goals. Teachers should be bold and correct grammar of ancient Chinese textbooks or grammatical terminology, so as far as possible with the middle school language teaching grammar system. Teachers should design some comprehensive issues related with the high school writings in classical style teaching, let the students analyze and solve, in order to improve the practice ability.

(5) Teaching methods need practical activities. Practical activities include two aspects: one is that exercise training. In ancient Chinese teaching, reading training must be outstanding, cultivating the students' ability of ancient prose reading, and reading ability raise cannot leave practical reading; Practical activities on the other hand is to let students out of the classroom, the application of knowledge. Can bring students went to the library and the library, feel the beauty of ancient books. Also can go to the places of interest in students, true feelings of the ancient atmosphere, use the knowledge analysis of linguistic phenomenon. All in all, rich and colorful activities can cultivate students' interest, to achieve the effect of their major.

(6) Rely on information technology to build comprehensive learning resources platform. Based on the technological learning is the basic requirement of modern education technology, rotating the birth of the classroom teaching mode based on the information technology support. Along with the continuously go deep into turning the classroom to explore, to cloud computing, Internet communication, mobile intelligent terminals, multimedia display continuously strengthen and production technology. Comprehensive these technology to realize data resources integrated management platform for the comprehensive learning resources is the development trend of the future, using the integrated platform to realize from the one-way teaching video to interactive learning resources, from the individual learning platform to learning community development, transformation from a fixed place to mobile learning, from teaching to pan in the learning support system.

\section{Conclusion}

Divorced from reality is the most serious problem of traditional ancient Chinese teaching, not only from the actual of students study in school, and from the actual students work after graduation. How to cultivate students' ability to apply the relevant knowledge of classic Chinese teaching and improve the level of classical Chinese teaching of high school, which become a problem urgently to be solved in normal colleges of ancient Chinese language teaching. Turn the classroom teaching model, provides a new way to solve this problem. As long as educators keep up the pace, renewal education idea, adhere to the quality education for the principle, constant exploration of science teaching methods, give full play to teachers' leading role and students' main body role, is bound to bring new life to the ancient Chinese teaching.

\section{Acknowledgement}

This work is supported by teaching reform project of Bohai university (BDJG-15-YB-C-015): Linking Practice on Ancient Chinese Teaching and Classical Chinese Teaching in Middle School based on Rotation Classroom.

\section{References}

[1] Z. Yan, L. Yang, "Comparison and thinking of flipped classroom and traditional teaching," Journal of Chifeng University (Natural Science Edition), vol. 31, no. 23, pp. 196-197, 2015.

[2] C. L. Zhang, "Thinking about the Anthology Teaching of Ancient Chinese," Journal of Xichang College (Social Science Edition), vol. 24, no. 3, pp. 1-2, 2012.

[3] M. J. Wen, "Some selected works of ancient Chinese teaching should be strengthened," Modern Chinese, vol. 53, no. 3, pp. 6-8, 2015. 
[4] J. Zhong, "On the teaching reform of common words in ancient Chinese," Literature Education, vol. 8, no. 5, pp. 6-8, 2012.

[5] W. G. Shi, "Research on the teaching situation and reform measures of the ancient Chinese in colleges and universities," Journal of Qiqihar University (Philosophy \& Social Science Edition), vol. 44, no. 3, pp. 174-176, 2015.

[6] X. J. Zhu, "On how to carry out the teaching of classical Chinese in middle school," Language Teaching In Middle School, vol. 27, no. 10, pp. 59-62, 2005.

[7] Y. Q. Mu, "Classical Chinese teaching in middle school," Developing, vol. 17, no. 9, pp. 145, 2010.

[8] Q. Y. Wei, "Ancient Chinese and classical Chinese teaching," http://wenku.baidu.com/link?url=CkRFIHPrjJ_gEbG7-ZicWd2eoOxN93n_ZWcDycch0R2clJf hjdetxpaALkqYYbQW22HokglzzIGPD2fSBFmrL-m7Xtl1KF2HbL3FKdwmZpK, 2016-4-23.

[9] L. F. Nong, "The Embodiment of the Cultivation of Students' Ability to Teach Classical Chinese in Ancient Chinese Teaching," Journal of Nanning Junior Teachers College, vol. 21, no. 2, pp. 60-63, 2004.

[10] L. He, "On the Linking Problems between Ancient Chinese Course in Normal Universities and Classical Chinese Teaching in Middle Schools," Education and Teaching Research, vol. 29, no. 3, pp. 81-84, 2015.

[11] B. Q. Liu, "Technical characteristics and development trend of the flipped classroom," The Chinese Journal of ICT in Education, vol. 21, no. 18, pp. 11-15, 2015.

[12] J. F. Dong, "Suggestions on the implementation of the flipped classroom teaching in primary and middle schools," Teaching \& Adimistration, vol. 32, no. 18, pp. 76-78, 2015. 